See Article page 154 .

\section{Commentary: Does not unexpected mean expected?}

\author{
Charles B. Huddleston, MD, and \\ Andrew C. Fiore, MD
}

Heart transplantation for failed Fontan circulation is a complex undertaking for all the reasons listed in the outstanding review of this topic by Rajab and Jaggers. ${ }^{1}$ No one argues that the Fontan operation (and care of single-ventricle patients in general) has evolved as a tremendous advance in congenital heart disease. However, lingering doubts about longevity must be present in the minds of those caring for these patients living with half of a heart. The final sentence sums it up nicely - "transplantation following Fontan palliation is......not a failure, rather a not unexpected outcome..." That is what we now offer children born with complex single-ventricle anomalies, a not unexpected outcome of replacing the heart altogether. However, are we now saying that heart transplantation is a universal eventuality for patients fortunate enough to have survived at least 2 prior palliative operations and then the Fontan procedure? That seems a daunting proposition for parents and their children.

Let's do some math first. On average, there are approximately 1000 Fontan procedures performed annually in the United States, according to the annual Society of Thoracic Surgeons database. The operative survival is around $98 \%$ and the 20-year survival for that group is around $82 \%{ }^{2}$ This means approximately 800 patients will be added to the rolls of adults potentially requiring heart transplants, assuming this is the not unexpected outcome. Currently, of the 3000 adult heart transplants performed annually in

From the Department of Surgery, St Louis University School of Medicine, St Louis, Mo.

Disclosures: The authors reported no conflicts of interest.

The Journal policy requires editors and reviewers to disclose conflicts of interest and to decline handling or reviewing manuscripts for which they may have a conflict of interest. The editors and reviewers of this article have no conflicts of interest.

Received for publication May 8, 2020; revisions received May 8, 2020; accepted for publication May 20, 2020; available ahead of print July 2, 2020.

Address for reprints: Charles B. Huddleston, MD, Department of Surgery, St Louis University School of Medicine, 1465 S Grand Blvd, St Louis, MO 63104 (E-mail: Charles.huddleston@ @ealth.slu.edu).

JTCVS Open 2020;3:162-3

2666-2736

Copyright $@ 2020$ The Authors. Published by Elsevier Inc. on behalf of The American Association for Thoracic Surgery. This is an open access article under the CC BY-NCND license (http://creativecommons.org/licenses/by-nc-nd/4.0/).

https://doi.org/10.1016/j.xjon.2020.05.007
Check for updates

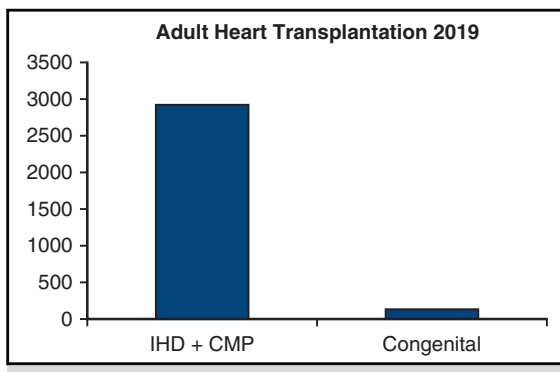

This bar graph demonstrates the striking discrepancy between adult heart transplantation for CHD and the combination of CMP and IHD.

CENTRAL MESSAGE

It is unlikely that patients undergoing the Fontan operation will have a normal life expectancy, yet it is both impractical and unlikely that all these patients will ultimately undergo heart transplantation.

the United States, about 130 are for congenital heart disease of all types (Figure 1). ${ }^{3}$ It is unrealistic to believe that heart transplantation for congenital heart disease will increase 30fold to accommodate these patients. This assumes that all Fontan patients will ultimately experience failure (ie, the not unexpected outcome). It is also unrealistic to think that adult transplant cardiologists will enthusiastically list these complex patients in the first place.

But wait. Maybe transplantation is not the unexpected outcome. In a multicenter study in Japan of 604 Fontan patients surviving to adulthood, the 5-year survival beyond age 24 years was a remarkable $93 \%$. None of these patients were transplanted. ${ }^{4}$ In reviewing many single-center studies of heart transplantation for failed Fontan patients, the average age at transplant is mid-teens and there is a relative paucity of adults in these series. Granted, these centers are pediatric, but many congenital heart programs generally perform complex procedures (including transplants) on their adults in the pediatric centers. It is difficult to draw conclusions from observations such as these, but it is entirely possible that once a Fontan patient has survived teenage years, their longevity as adults is actually quite good. Do we think that all Fontans are destined to fail? It seems unlikely that these patients will have a normal life expectancy, but the complete story is yet to be told. Maybe transplantation is not the unexpected outcome! 


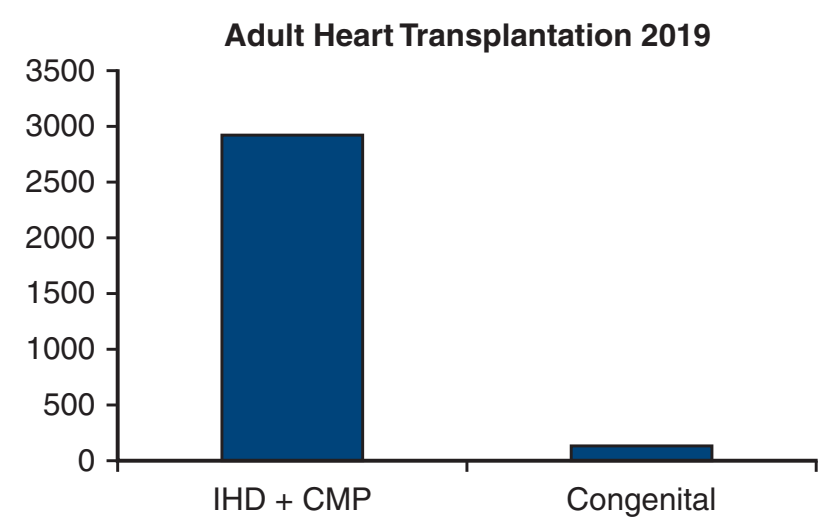

FIGURE 1. Bar graph demonstrating the striking discrepancy between adult heart transplantation for congenital heart disease ( $C H D)$ and the combination of cardiomyopathy $(C M)$ and ischemic heart disease (IHD) ischemic heart disease.

\section{References}

1. Rajab K, Jaggers J. Transplantation in Fontan failure: the final stage. J Thorac Cardiovasc Surg Open. 2020;3:154-9.

2. Poh CL, d'Udekem Y. Life after surviving Fontan surgery: a meta-analysis of the incidence and predictors of late death. Heart Lung Circ. 2018;27:552-9.

3. Organ Procurement and Transplantation Network. National data. Available at: https://optn.transplant.hrsa.gov/data/view-data-reports/national-data/. Accessed June 13, 2020.

4. Ohuchi H, Inai K, Nakamura M, Park IS, Watanabe M, Hiroshi O, et al. Mode of death and predictors of mortality in adult Fontan survivors: a Japanese multicenter observational study. Int J Card. 2019;276:74-80. 